\title{
BUILDING ENERGY MODELING (BEM) OF CULTURAL HERITAGE. CASE STUDY: 28 DRAGOMAN ST, VARNA, BULGARIA
}

\author{
Nadya Stamatova, Veselin Vasilev, Antoni Angelov, Orlin Perfanov
}

Abstract: This paper presents the efforts of the team of the R\&D SME Architectural Spies EOOD of creating a building energy model (BEM) of the cultural heritage building at 28 Dragoman St and 11 Bdin St, Varna, Bulgaria. Two types of BEMs are presented: based on BIM and based on FLIR thermal surveys. Know-how of producing volumetric $3 D$ models based on $2 D$ thermal scans is the specific scientific contribution of the authors. The BEM will be a part of AR and VR applications developed by the same team in the frames of the H2020 project BIM-SPEED (Harmonized Building Information Speed way for Energy-Efficient Renovation).

Keywords: building energy model, BEM, building information model, BIM, digitization, digitalization, cultural heritage, $C H$, energy efficiency, EE, thermal scans, thermal survey, FLIR

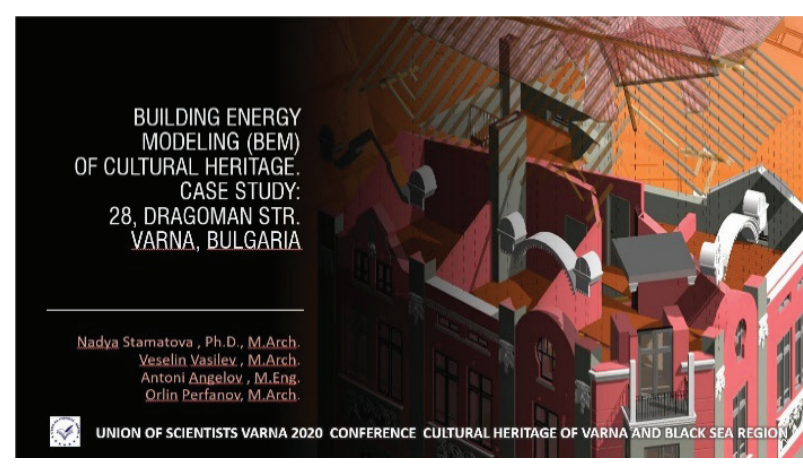

Fig. 1. English title slide of the presentation at the conference on 27 September 2020

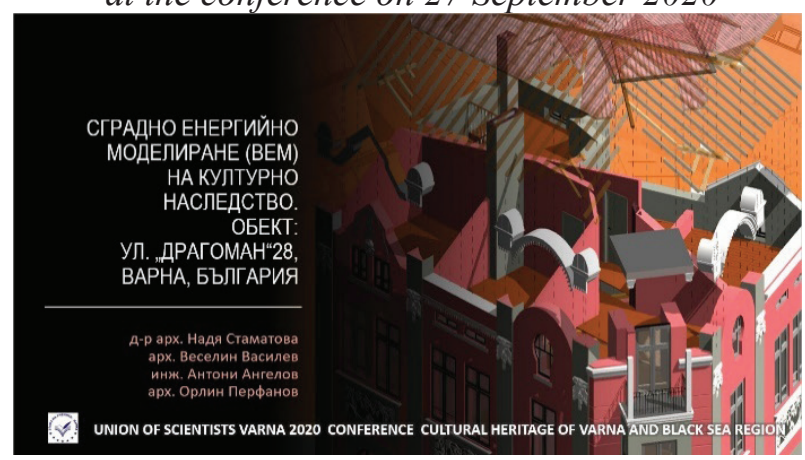

Fig. 2. Bulgarian title slide of the presentation at the conference on 27 September 2020

The cultural heritage building at the corner of the streets Dragoman and Bdin in the center of the city of Varna is one of the demo sites (Fig.3,4), included in the H2020 project BIM-SPEED (Harmonized Building Information Speedway for Energy-Efficient Renovation) (3) for extended reality (XR) (AR/AV/VR) demonstrations, developed by Architectural Spies EOOD (2).

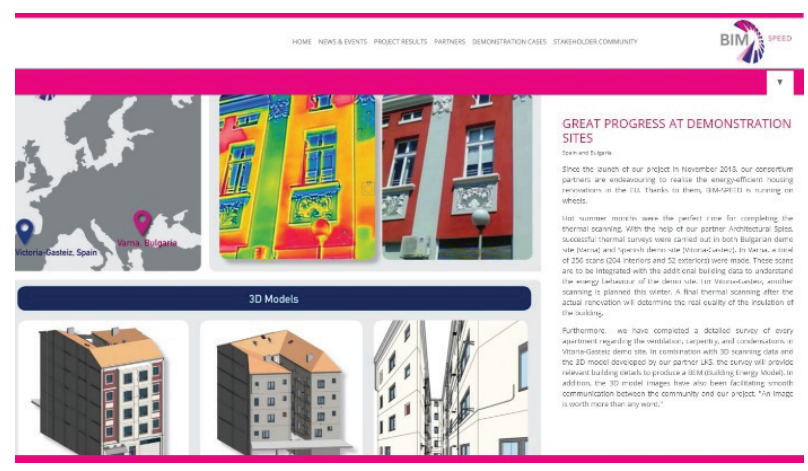

Fig. 3. Page about the thermal surveys at demo sites done in Bulgaria and Spain $(2,3)$

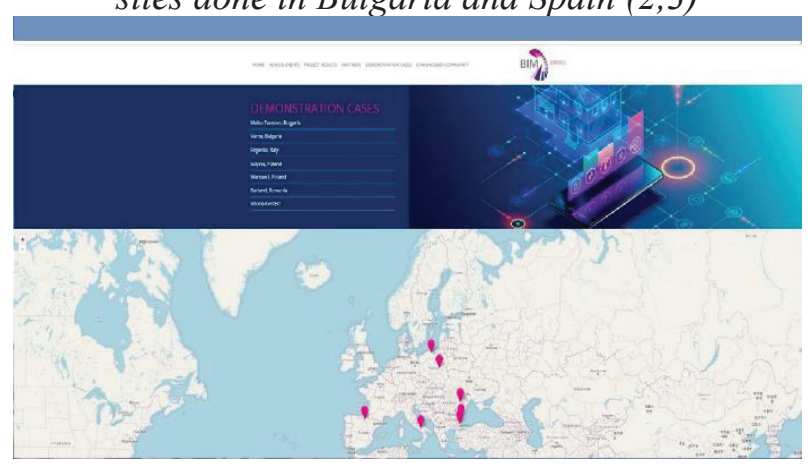

Fig. 4. Map of the BIM-SPEED demo sites, incl. both Bulgarian demo sites (3)

The creation of BIM of the case study building is a subject of the other publication of the same authors in this journal. The Revit BIM asset was a base for creating BEM (1). To create a building energy model we used the Revit builtin functionality and analytic tools (spaces, HVAC zones, energy model, solar study). Following steps we were required to create ean nergy model 
to further analyze and visualize the efficiency of the building: create, load and attach proper architectural and analytic materials with correct physical and thermal asset properties;

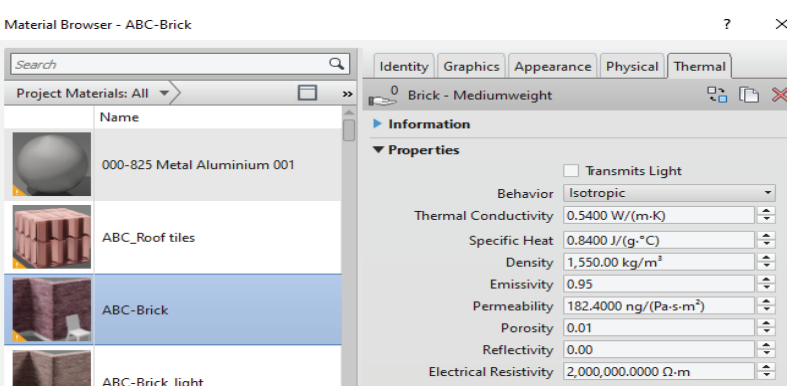

Fig. 5. Material properties

define HVAC zones properties: building type, construction type-interior and exterior components, HVAC installations type, structural elements;

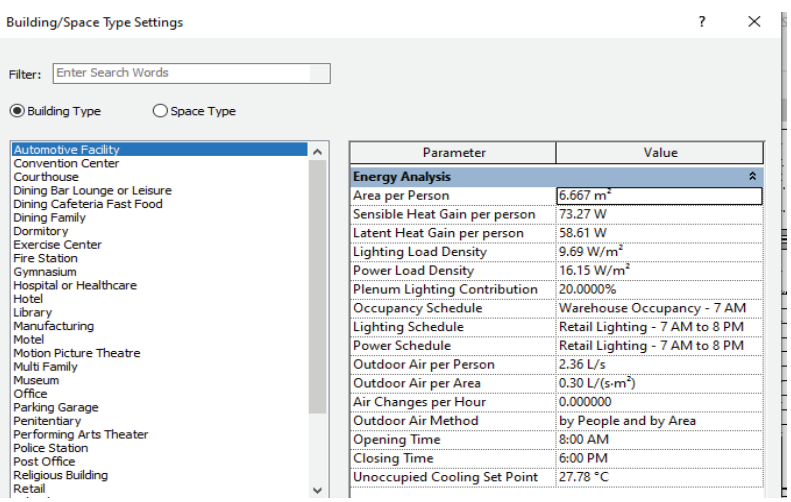

Fig. 6. HVAC zone definition

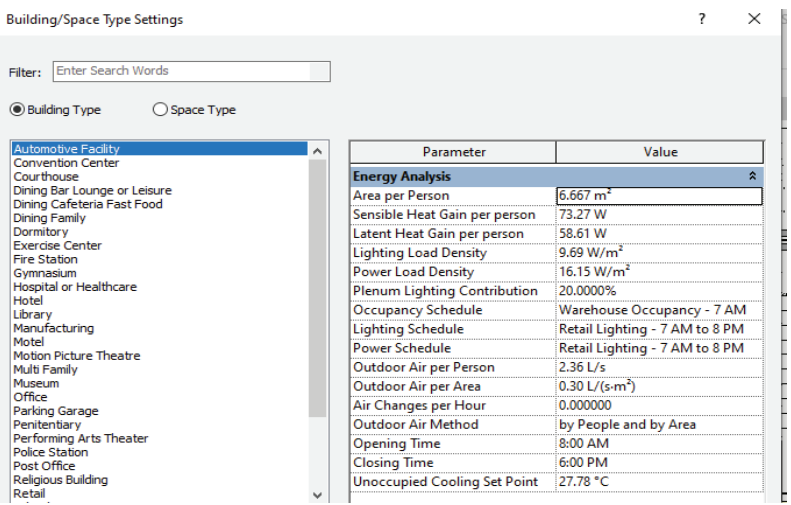

Fig. 7. Building type definition

definitions of analytic construction heat transfer values and measuring units-for roofs, exterior and interior walls, slabs, floors, doors, windows; regarding density, heating and cooling loads, coefficient of heat transfer, thermal resistance, thermal mass, thermal conductivity, specific heat, permeability;

create energy analysis based on building model; also create energy model and heating and cooling loads.

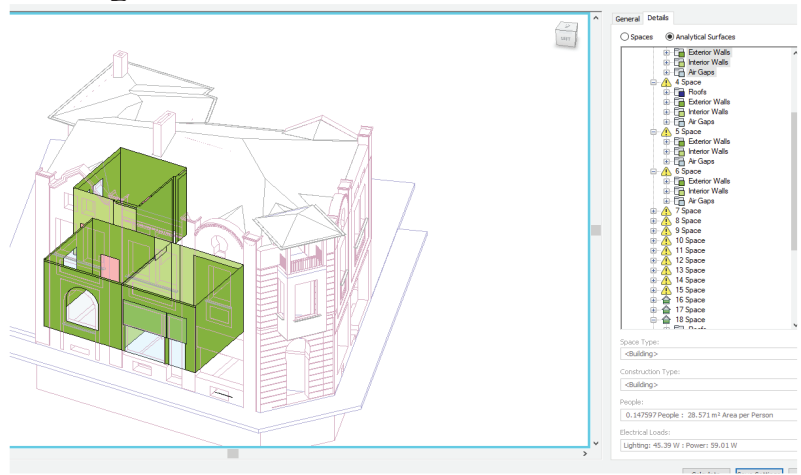

Fig. 8. BEM in progress, based on BIM.

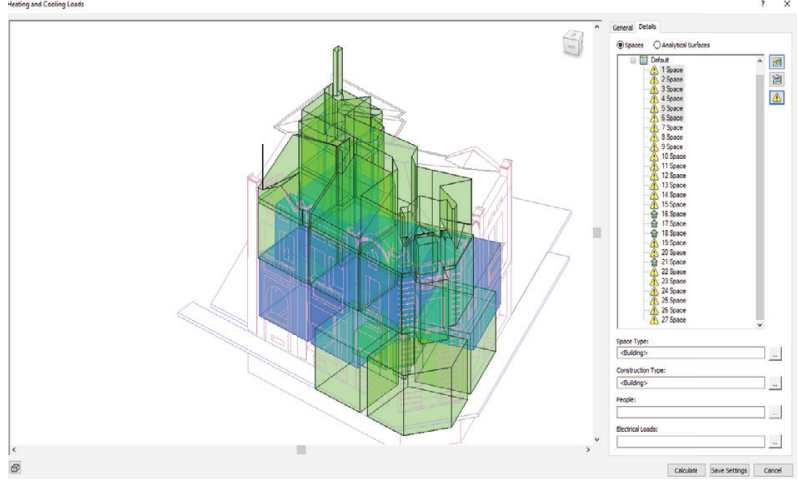

Fig. 9. BEM in progress, based on BIM.

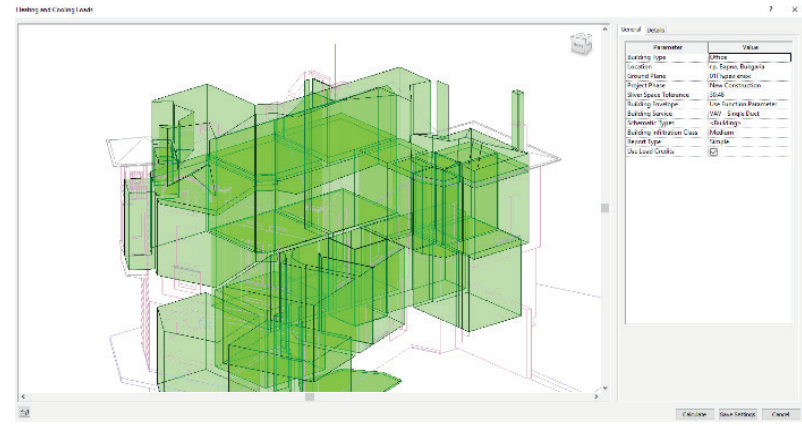

Fig. 10. BEM in progress, based on BIM

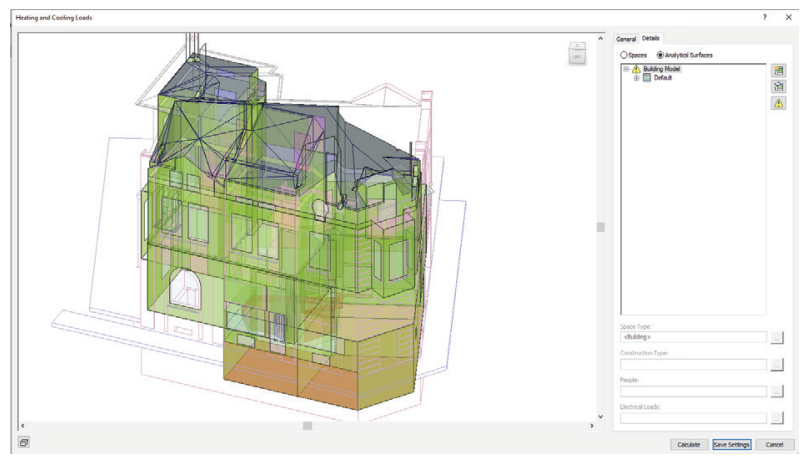

Fig. 11. BEM based on BIM 
All the results from the BEM model and energy analysis can be recorded as .xls sheets or reports for further analysis.

To create a solar study (Fig. 12, 13) as an essential part of the energy analysis, it is necessary to put the building into correct GIS location. It could be visualized with the sun shading for a single day/time or animated with the solar activity for a longer period of time.

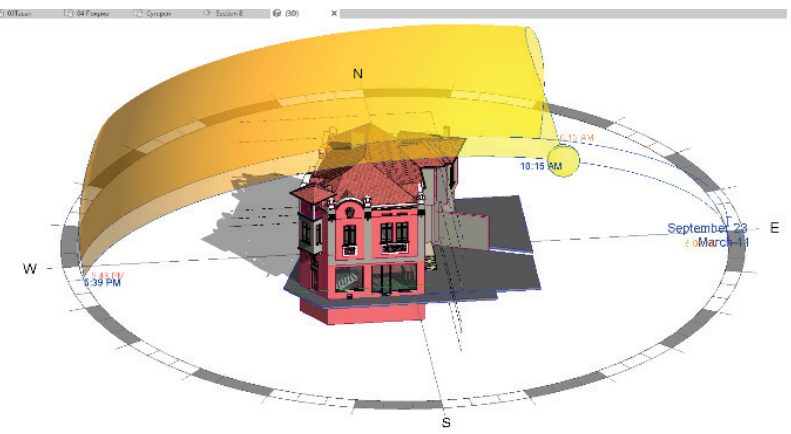

Fig. 12. Solar study

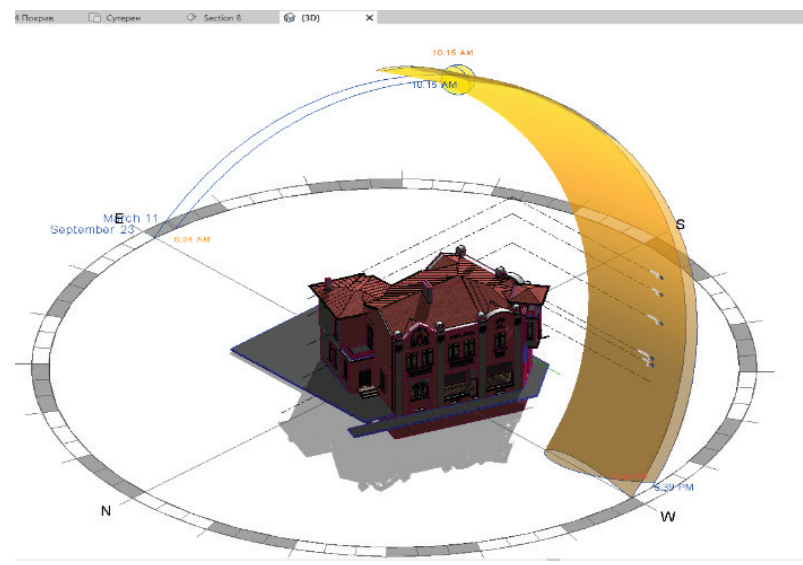

Fig. 13. Solar study

The authors' team developed a know-how for creating energy models based on 2D thermal scans (Fig.14, 16). The demonstration building, a subject of this case study, is monitored during a 4-year period. FLIR (6) scans are performed at least twice per year: in the winter and in the summer. The monitoring period began in the winter of $2018 / 2019$. At that time the renovation of the building still had not started. In the summer of 2019, the facades facing both streets were renovated and those in the yard accessed from Dragoman St underwent partial renovation. The super-fine Altermo heat insulation, a Russian production borrowed from the aeronautical industry, was used. In September 2020, the two inner facades were still not renovated. The project of Nadya Stamatova and Maria Hlebarova for facade renovation of the cultural heritage building was nominated at the annual architectural exhibition in Constanta, Romania for projects from Romania, Bulgaria, and Moldova (Fig. 15).

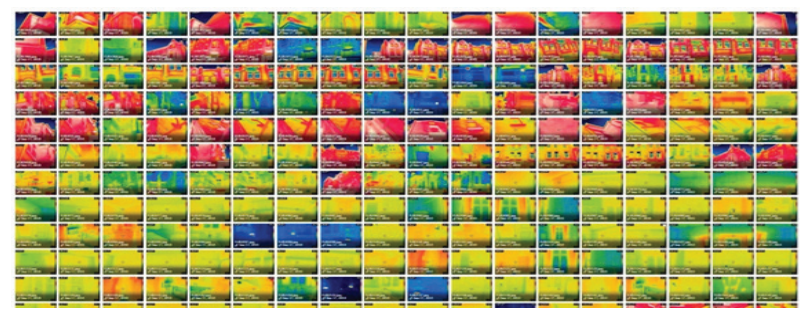

Fig. 14. FLIR thermal scans of the building (6)

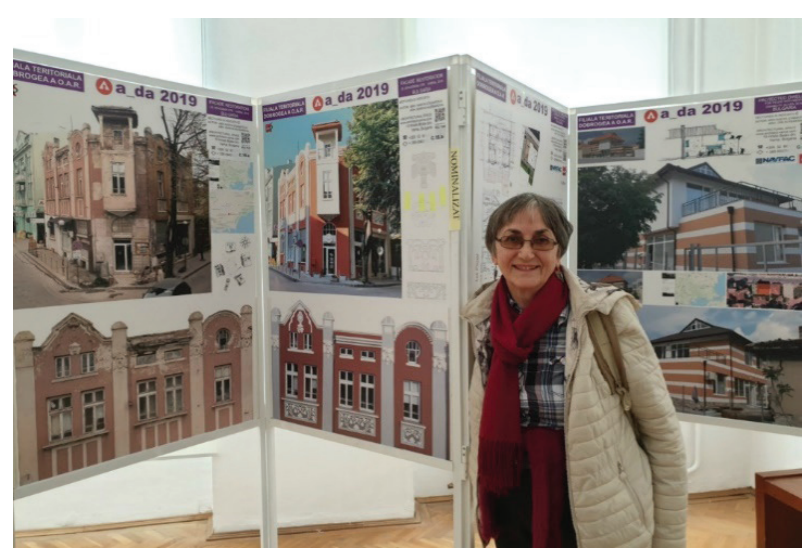

Fig. 15. The nominated project of N. Stamatova and $M$. Hlebarova at the architectural exhibition "a_da" 2019 in Constanta, Romania

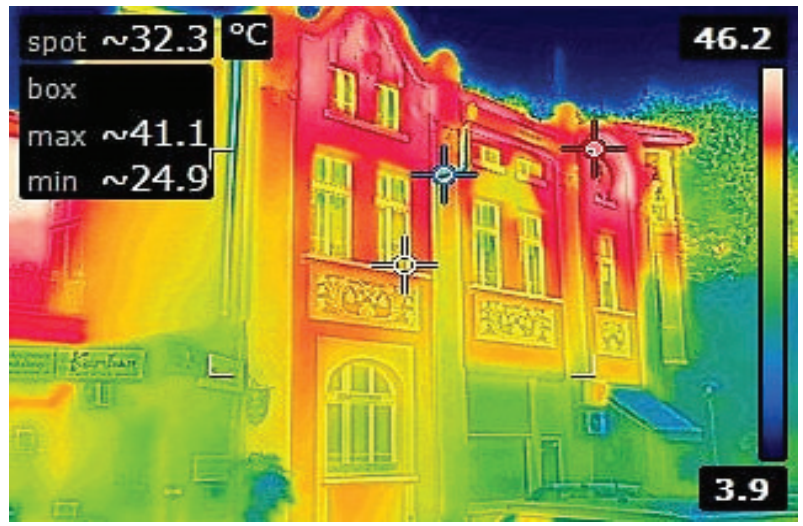

Fig. 16. Example of a thermal scan (6) 


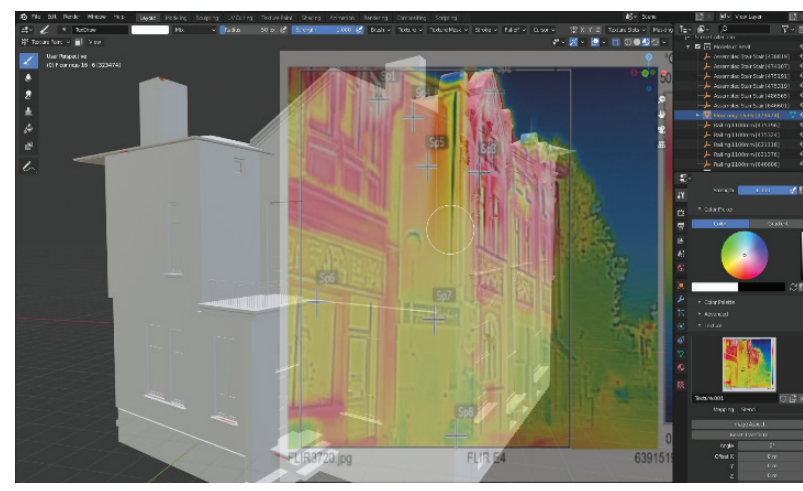

Fig. 17. Creation of BEM in Blender environment (4, 5) based on FLIR scans (6)

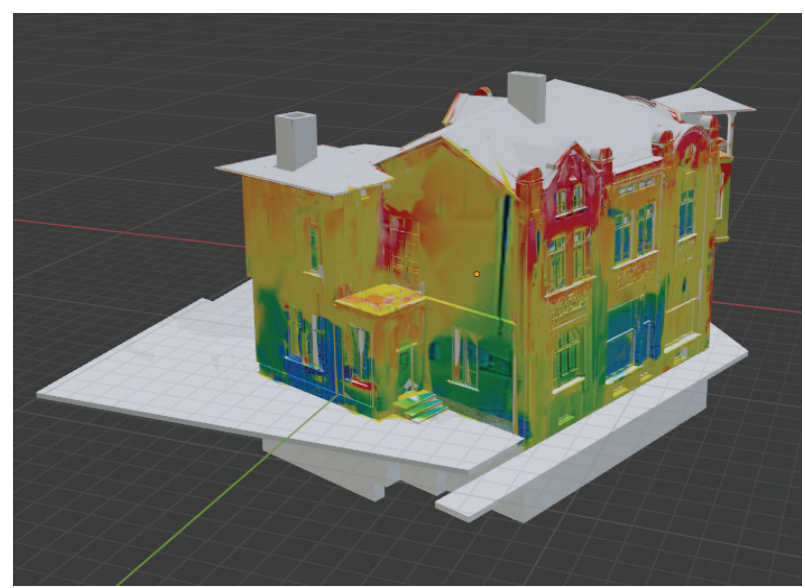

Fig. 18. BEM in Blender environment $(4,5)$ based on FLIR scans (6)

The thermal image provides real information that can be compared to the simulation data for a variety of situations, including evaluation of the quality of the tools and work in construction and repair. The thermal $3 \mathrm{D}$ model is more comprehensive than the photos for most people although it may have slight inaccuracies as compared to the raw thermal image.

The "sticking" of the thermal data as a texture on the CAD model of the building is currently a manual task but in the near future it will be automated and thus the inaccuracies will be reduced. The process has 3 factors: position of the camera based on the model, direction of the camera, and focal length of the camera. The last one requires constant adjusting in the manual process due to the autofocus of the thermal camera. With the 3 values known the automation of the process would require a simple software to put on the texture. Collecting the 3 variables out of which position and direction of the camera can be collected via repurposing the augmented reality software for using a feature of the building (a door, for example) as a basis and then tracking the position of the camera. A more difficult to create software could use a photogrammetry method for the positions of the cameras. However, any adjustment to a photogrammetry software would require a deep understanding of its programming code, which is far from simple. And this is not a small fix as it would need to recognize the CAD model and align it to the photogrammetry model inside its software. However, that would allow already existing thermal images to be applied as textures in an automated software without any special requirements to the equipment on site where the thermal data is collected.

\section{References:}

1. Kirby, L., Krygiel, E., Kim, M. (2017). Mastering Autodesk Revit 2018, Sybex, ISBN: 978-1-119-38672-8 pp.516-522

2. Architectural Spies EOOD. Available at: http://architecturalspies.com. Accessed: 29 October 2020.

3. H2020 BIM-SPEED Project. Available at:

https://bim-speed.eu/en. Accessed: 29 October 2020.

4. Blender Foundation. Available at: https:// www.blender.org. Accessed: 29 October 2020.

5. Blender Foundation. Available at: https://docs.blender.org/manual/en/latest. Accessed: 29 October 2020.

6. FLIR Systems, Inc. Available at: https://www.flir.com/products/flir-tools. Accessed: 29 October 2020.

\section{Contacts:}

Nadya Stamatova, Ph.D., M.Arch. orcid.org/0000-0002-5265-7958 nadya.stamatova@gmail.com Veselin Vasilev, M.Arch. v_vasilev2001@yahoo.com Antoni Angelov, M.Sc.eng. antoniangelov@gmail.com Orlin Perfanov, M.Arch. orlin.perfanov@gmail.com 